\title{
Analysis on the External Causes of Learning Burnout in Normal University Students*
}

\author{
Jie Zhang \\ China West Normal University \\ Nanchong, China 637000
}

\author{
Zhu Zhu \\ China West Normal University \\ Nanchong, China 637000
}

\begin{abstract}
Normal college students shoulder the historical mission of promoting the basic education of the country, and the quality of their training is directly related to the reform and development of basic education. At present, the learning situation of normal university students is not optimistic, and the phenomenon of learning burnout is becoming more and more prominent. Thus, this paper attempts to analyze the external causes of learning burnout in normal university students from the aspects of society, school and family.
\end{abstract}

Keywords-normal college students; learning burnout; external reasons

\section{INTRODUCTION}

In 1981, Pines et al. firstly proposed the concept of "learning burnout", which refers to the phenomenon of burnout that occurs in the process of learning. Schaufeli indicated that learning burnout is caused by excessive exhaustion of learning, emotional exhaustion, and lack of academic achievement. This definition briefly summarizes the causes of learner burnout and cognitive, emotional, and behavioral characteristics. Lian rong et al come up with one new idea-"When students have no interest or lack of motivation for learning but can't do it, they will feel bored, tired, depressed and frustrated, which will lead to a series of inappropriate behaviors to avoid learning"-from the definition above. Based on the description above, we think that students' learning burnout is contagious, a continuous and gradual process, and is related to the individual's unique psychological quality.

\section{THE INFLUENCE OF SOCIAL FACTORS ON THE LEARNING BURNOUT OF NORMAL COLLEGE STUDENTS}

\section{A. The Influence of Utilitarianism}

At present, the national society is in the period of economic transformation. The transformation of society inevitably made some negative concepts easily to fill the society such as utilitarianism, pragmatism and hedonism. They caused bad social atmosphere such as "learning well is not as good as marriage", "learning useless theory" and so

*This article is the result of the "Innovative Research on the Daily Ideological and Political Education Methods of College Students Based on Big Data" by the Counselor of the 2017 Basic Research Humanities and Social Science Project of China West Normal University (Project No. 17F026) on. In addition, some people with low academic qualifications became firstly the rich in society and the envied object of the public, and social phenomenon such as "official second generation", "rich second generation" was of presence. It leaded to the incorrect understanding of learning among normal college students, which made them impatient, eager for success and quick benefit, and then lost their learning motivation and produced learning burnout.

\section{B. New Media's Challenge of the Teaching Profession}

With the development of information globalization, new media based on modern Internet technology is changing with each passing day. It makes the micro-class education great progress such as MOOC, flipped classroom and other microcourses that is gathering all the top educational resources. Students can break the limitation of time and space to conduct online learning through Internet video streaming, which weakens teachers' career expectations to some extent.

\section{The Influence of the Openness of Teacher Selection and Recruitment}

The current teacher qualification certification system in China has broken the barrier of between normal education and non-normal education, and social employment mechanism is diverse. It makes the selection and employment of teachers more open. As described in the following aspects:

First of all, excellent graduates from non-normal colleges and universities have the opportunity to enter the ranks of basic education, resulting in an oversupply of primary and secondary school teachers. For example, in 2013, 10\% non-normal graduates entered the education system. Secondly, the influence of the normal university students' employment system and the employment mechanism of the society. For instance, many employers (primary and secondary schools) are unwilling to recruit undergraduates who lack practical experience, and prefer post-graduates with high academic qualifications or the aged teachers with rich work experience and professional ability. Besides, there is unfair phenomenon in the process of employment. These factors seriously dampen the enthusiasm, self-consciousness and initiative of normal college students. 
carried out excessively, the curriculum assessment is not in place, and the learning academic atmosphere is not strong. High-grade campus cultural activities are conducive to the improvement of students' comprehensive quality, but excessive development also affects the study of normal university students to a certain extent, which making them feel overwhelmed and tired of learning, and even appear absenteeism, late, early leave and other improper behavior. At the same time, the course assessment system is not implemented in place, which fails to form an effective binding force on the students who disturb the teaching order and violate the classroom discipline. construction of the normal major is not strengthened synchronously, and is even played down or weakened the features and advantages of the original teacher education. As a result, teachers' educational resources are relatively backward, which cannot provide an effective learning platform and the environment of good living for normal university students.

\section{B. The Curriculum System Is Out of Step with the Reform of Basic Education}

The curriculum structure of normal colleges is generally composed of subject professional courses, educational courses and practical courses. Subject specialized courses can provide a professional basis for normal university students in the future bishop discipline. Currently, all the basic education in China is subject specialized. Subject educational courses can best highlight the specialty of basic education for teachers and are also the basic characteristics of basic teaching. At the same time, the practice and novitiate of education also play a more important role in the cultivation of education professional quality of normal university students. Recently, the teaching curriculum structure and setting in some normal universities are out of sync with the needs of social employment, with a high proportion of professional courses, a relatively low proportion of education courses and educational practice courses, and there are the disconnection between theoretical learning and teaching practice. It reduces students' enthusiasm for learning to a large extent.

\section{Teaching and Student Management}

First of all, some teachers only pay attention to teaching, do not pay attention to education. In teaching, they only pay attention to students' cognitive process, ignore students' emotional education, and attach importance to the leading role of teachers, ignore the main position of students. It is difficult to carry out emotional communication and inquiry interaction between teachers and students in classroom and practical teaching. Secondly, the current assessment of students focuses on testing students' ability to remember knowledge, but lacks the evaluation of students' innovation ability. Most students review suddenly before the examination, and can pass the examination smoothly through the mechanical memorizing teaching materials. This not only fails to inspire students to think actively, consult materials, put forward their own unique views on research issues and train innovative thinking, but also weakens students' enthusiasm for learning and reduces their sense of learning self-efficacy. Thirdly, the campus cultural activities are

\section{THE INFLUENCE OF FAMILY FACTORS ON LEARNING BURNOUT OF NORMAL UNIVERSITY STUDENTS}

\section{A. The Influence of Family Economic Situation and Educational Cost Thought}

First of all, family economic situation has the most direct impact on students' learning attitude and behavior. Although normal university students with poor family economic level have strong willingness and motivation to study, they are busy with various social part-time jobs such as tutoring in order to subsidize school expenses and reduce family burden. It disperses their learning energy, which result in their relatively low learning investment. Secondly, the idea of education cost indirectly influences students' study in school through family expectation. The high cost of education puts great pressure on the family economy. Some families express that they are not willing to support the further education of normal university students, as long as normal college students can successfully graduate and find a job, and their expectations are low. Therefore, normal university students do not pay enough attention to their academic performance and muddle along in school. This discourages their enthusiasm and autonomy in learning.

\section{B. The Influence of Family Structure and Relationship (Atmosphere)}

In the aspect of family structure, there are single parent families, reorganized families, left-behind students' families. The kind of family structure is more likely to appear cold family relations, and disharmonious atmosphere, which makes it difficult for students to get the family care they deserve. These disadvantageous factors will often distract students' study attention and affect their study emotion. The investigation and research shows that most of the students with single parent, restructuring and left-behind students' family structure have the psychological characteristics of inferiority and sensitivity. They are unwilling to seek help when there are learning problems. It will lead to the formation of learning burnout in the course of time. Therefore, family relationship (atmosphere) positively affects students' learning state and negatively influences students' learning burnout.

\section{The Influence of Family Education Level}

The educational level of family members will have a certain impact on students' learning cognition and behavior. 
Students with higher family education level have more negative learning emotions than those with lower family education level. The reason may lie in: on the one hand, parents with higher education level have too high expectations of their children, resulting in greater psychological pressure on college students, causing them to have fear of learning and discouraging their enthusiasm for learning. On the other hand, highly educated parents tend to take too much control over their children's study, making them dependent on learning and leading to a lack of motivation for independent learning.

\section{CONCLUSION}

Learning burnout, a common problem encountered in the construction process of studying atmosphere and School spirit in universities, is ubiquitous among college students, and highly concerned by scholars and education management workers. Currently, there are some learning burnout phenomena in normal university students, including ambiguous learning objectives, negative learning emotions, and weak learning achievement. In view of the fact described above, we try to analyze and discuss the external reasons that affect the learning burnout of normal university students from the aspects of society, school and family on the basis of previous studies.

\section{REFERENCES}

[1] Schufeli W B,Martinez I m. Pinto A m. Burnout and engagement in university students; Journal of cross-cultural Psychology, 2002,33(5): 464-481.

[2] Pines A,Aronson E, Kafry. Burnout:From Tedium to personal Grronth. Free Press, New York.

[3] Lian rong, Yang lixian, wu orchid."The relationship between college students' professional commitment and learning burnout and the development of scale" psychological journal, 2005,15 (2): 118-120. 